\title{
Pure White Cell Aplasia an exceptional condition in the inmunological conundrum of thymomas: Responses to inmunosupresion and Literature Review.
}

\author{
Roberto Céspedes López ${ }^{1}$, Elena Amutio², Xabier Martín Martitegui ${ }^{3}$, Amaia Balerdi \\ Malcorra $^{2}$, Lucia Insunza Oleaga ${ }^{4}$, Maite Moreno ${ }^{2}$, Javier Arzuaga-Mendez ${ }^{5}$, and Juan \\ García-Ruiz ${ }^{3}$ \\ ${ }^{1}$ Banc de Sang i Teixits \\ ${ }^{2}$ Gurutzetako Unibertsitate Ospitalea \\ ${ }^{3}$ Hospital Universitario Cruces \\ ${ }^{4}$ Hospital San Eloy \\ ${ }^{5}$ Cruces University Hospital
}

September 25, 2021

\begin{abstract}
Thymomas are tumours frequently associated with autoinmune manifestations or immunodeficiencies like Good syndrome. In rare cases, pure white cells aplasia (PWCA) has been described in association with thymomas. PWCA is characterized by agranulocytosis of autoinmune background primary refractory to granulocyte colony-stimulating factor (G-CSF). It is necessary to use inmunosupressor drugs.
\end{abstract}

Title: Pure White Cell Aplasia an exceptional condition in the inmunological conundrum of thymomas: Responses to inmunosupresion and Literature Review.

Authors: Céspedes López $\mathrm{R}^{1}$, Amutio Díez E ${ }^{2}$, Martín Martitegui $\mathrm{X}^{2}$, Balerdi Malcorra $\mathrm{A}^{2}$, Insunza Oleaga $\mathrm{L}^{3}$, Moreno Gámiz M², Arzuaga Méndez J², García-Ruíz JC² .

${ }^{1}$ Hematology, Banc de Sang i Teixits BST-GIRONA, Girona, Spain. ${ }^{2}$ Hematology, Hospital Universitario Cruces, Barakaldo, Spain ${ }^{3}$ Hematology, Hospital San Eloy Barakaldo, Spain.

Corresponding Author : Roberto Céspedes López, Hematologist, Banc de Sang i Teixits BST-Girona, Girona, Spain. Email: rcespedes@bst.cat

Key Clinical Message: Pure White Cell Aplasia associated to thymoma is a rare autoinmune condition which no respond to treatment with G-CSF. It is neccesary the use of immunosuppressors to allow granulocyte recovery. Without treatment it could be fatal.

Abstract: Thymomas are tumours frequently associated with autoinmune manifestations or immunodeficiencies like Good syndrome. In rare cases, pure white cells aplasia (PWCA) has been described in association with thymomas. PWCA is characterized by agranulocytosis of autoinmune background primary refractory to granulocyte colony-stimulating factor (G-CSF). It is necessary to use inmunosupressor drugs.

Key Words: Thymoma, Pure White Cell Aplasia, Agranulocytosis, Granulocytopenia and Good's Syndrome. 


\section{Introduction}

PWCA is an haematologic disorder characterized by agranulocytosis with absence of myeloid precursors in bone marrow with an eritropoiesis and megacariopoiesis preserved. It has been associated with drugs, infectious diseases and autoinmunity ${ }^{1}$. Thymomas and thymic carcinomas may present autoinmune phenomena fundamentally: miastenia gravis (MG) up to $50 \%$ of the cases and pure red cell aplasia (PRCA) up to $5 \%$ of the cases ${ }^{2}$. However, the incidence of thymoma and PWCA is extremly rare by existing few reports ${ }^{3}$.

We conducted a search for articles registered in Pub-Med between 1950-2021, which were available in English. The keywords used were: Thymoma, Pure White Cell Aplasia, Agranulocytosis and Granulocytopenia.

\section{Case}

A 33-year-old male, with a history of admission to the intensive care unit for influenza A in 2016, consulted for skin lesions at primary care and was given treatment with amoxicillin/clavulanic acid and ibuprofen in October 2020. Three days later, he consulted the emergency department of our hospital due to worsening of clinical symptoms with thermometric tympanic fever of $40.5^{\circ}$, blood pressure $123 / 67 \mathrm{mmHg}$ and heart rate 98 beats per minute. He had not taken any other medication or drugs previously. Examination revealed a $2 \mathrm{~cm}$ branching ulcer on the jugal mucosa and four indurated skin lesions with an erythematous halo and necrotic centre, suggestive of gangrenous ecthyma (Fig1), the largest on the left hand measuring $3 \mathrm{~cm}$ in diameter.

Laboratory tests on admission showed normal renal, liver and thyroid function, C-reactive protein 3104.7 nmol/L (Normal Range 0-1100), Procalcitonin $1400 \mathrm{ng} / \mathrm{L}$ (NR 0-100), Haemoglobin 139 g/L (NR 130160), Platelets $161 \times 10^{9} / \mathrm{L}$ (NR 150-450), Leukocytes $0.5 \times 10^{9} / \mathrm{L}$ (NR 4.5-10) (Revised formula: $100 \%$ lymphocytes). IgG $4.79 \mathrm{~g} / \mathrm{L}$ (NR 6-17), IgA $0.57 \mathrm{~g} / \mathrm{L}$ (NR 0.7-4) IgM $0.69 \mathrm{~g} / \mathrm{L}$ (NR 0.4-2.30), C3 and C4 normal. Anti-nuclear, anti-neutrophil (ANCA), anti-Musk and anti-acetylcholine antibodies were negative. Serology for HBV, HCV and HIV were negative; he tested IgG+ against EBV and CMV. Peripheral blood flow cytometry analysis showed $\mathrm{CD} 4^{+} / \mathrm{CD}^{+}$ratio inversion 0.56 , low B lymphocytes, but no data suggestive of B/T clonality. Blood cultures, nasal swab for $S$. aureus as well as bacterial culture and PCR of skin lesions were negative. Bone marrow aspirate showed normal erythroid and megakaryocytic series. Granulocytic series represented $3.6 \%$ of the total cellularity, promyelocyte maturational arrest was observed. There was no evidence of dysplasia or increased blast cellularity, karyotype 46, XY. CT scan revealed an anterior mediastinal mass measuring $47 \times 71 \times 60 \mathrm{~mm}$ with no evidence of locoregional infiltration (Fig2) . A biopsy of the mass was performed with an anatomopathological result of mixed type AB thymoma.

On admission, empirical antibiotic therapy was started with Piperacillin/tazobactam and daptomycin with improvement of symptoms and resolution of fever in the following days. With the initial diagnosis of agranulocytosis, G-CSF $480 \mathrm{mcr} / 24 \mathrm{~h}$ was added to the treatment for 13 days with no increase in the neutrophil count, so it was discontinued. Once the diagnosis of thymoma was confirmed and with the suspicion of related PWCA, single dose of intravenous Inmunoglobuline G (IVIG) $1 \mathrm{~g} / \mathrm{Kg}$ and ciclosporine (CyA) with target levels $200-300 \mathrm{ng} / \mathrm{dl}$ were initiated. On day +10 there were signs of granulocytic recovery: neutrophils $0.17 \mathrm{x}$ $10^{9} / \mathrm{L}$ in peripheral blood, so G-CSF was associated; on day +14 from the start of CyA the patient reached neutrophils $17 \times 10^{9} /$ L. Thymectomy was performed on day +21 , without remarkable incidents.

After thymectomy, CyA tappering was started. Six months later, CyA was discontinued, and neutrophil count remains still stable. Inmunnoglobuline levels, $\mathrm{CD} 4^{+} / \mathrm{CD} 8^{+}$ratio and $\mathrm{B}$ lymphocytes returned to normal values. The patient has not presented any infectious, CyA-related or post-surgical complications during follow-up.

\section{Discussion}

Immunity may be impaired in patients with thymoma. Thymoma-associated immunodeficiency is known as Good's syndrome and includes hypogammaglobulinaemia, decreased or absent B lymphocytes, CD4 ${ }^{+} / \mathrm{CD} 8^{+}$ inversion and decreased $\mathrm{T}$ lymphocytes. In addition, autoimmune manifestations may occur ${ }^{4}$. The etiology of thymoma related PWCA is still unknown, but it appears to have an autoimmune background. Growth 
inhibition of granulocytic and macrophage colony-forming units exposed to different concentrations of serum from these patients has been observed. This finding suggests the presence of an immunoglobulin against immature myeloid cells, indicating an alteration of B cells and humoral immunity ${ }^{5}$. Conversely, the response to anti-calcineurin immunosuppressors in these cases, as in PRCA, points to an alteration in $\mathrm{T}$ cells and cellular immunity ${ }^{6}$. Thymus is the organ where $\mathrm{T}$ cell maturation and TCR gene rearrangement occurs. Besides, it is the place where negative selection of autoreactive $\mathrm{T}$ cells and positive selection of $\mathrm{T}$ cells capable of recognising MHC presented antigens take place ${ }^{7}$. In this sense, several causal mechanisms for the loss of self-tolerance in thymoma patients have been proposed: (1) Immaturity of neoplastic T cells that would allow the escape of autoreactive lymphocytes, (2) Neoplastic genetic alterations that would predispose to the appearance of autoimmunity such as decreased expression of HLA-DR and (3) Theory of combined dysregulation of cellular and humoral immunity, an autoreactive $\mathrm{T}$ cell would activate a B cell to produce autoantibodies ${ }^{8}$.

Surgery to resect tumour tissue is the standard treatment for patients with thymoma. Thymectomy appears to have a positive impact on the autoimmune clinic by removing the neoplastic tissue, which seems to provide the antigenic stimulus for autoreactive cells. It has been reported the case of a patient with thymoma and granulocytopenia in whom a decrease in anti-pANCA antibody titre and elevation of granulocytes in peripheral blood was observed after thymectomy ${ }^{9}$. However, in other cases neutropenia has not resolved after thymectomy and a second line of treatment is necessary ${ }^{10,11}$. The medical treatment of these patients is not established currently, due to low incidence of cases. Several strategies have been used to increase granulocyte counts (Table I). GCS-F and IVIG normally have no impact in granulocytic count ${ }^{12}$. Of the 24 patients collected 13 survive, all of them receive some immunosuppressive treatment (CyA 6 patients, Azathioprine 2, Corticoid 2, Alemtuzumab 1, Chemoterapy 1 and plasmapheresis 1) which reinforces the idea of a combined surgical and immunosuppressive treatment for these patients.

CyA has demonstrated favourable responses in these patients. It has been used with target trough levels of 200-400 ng/mL and monitoring toxicities. Granulocytic recovery occurs within 7 to 10 days. Maintenance treatment has usually been applied, with CyA tappering until its total suspension after 4-6 months ${ }^{5,10}$. Others have used extended treatment with CyA and prednisone in decreasing doses for up to 20 months after thymectomy $^{12}$.

Alemtuzumab has been successfully used as an immunosuppressor in autoimmune bone marrow failures. In two cases of PWCA Alemtuzumab has achieved complete response in the first month ${ }^{13}$. Alemtuzumab has been useful in the treatment of a patient with PWCA and thymoma, after failure of G-CSF and plasmapheresis, achieving granulocyte recovery in 12 days. However, agranulocytosis relapsed 5 months later and was treated with a new cycle of Alemtuzumab associated with CyA and maintenance mycophenolate ${ }^{14}$.

A case has been described of a paciente with MG thymectomised, who relapsed after 12 years with MG and de novo PWCA. In this case, plasmapheresis was started with improvement of the MG symptoms as diagnosis, but there was no change in the granulocyte count after 15 sessions. Azathioprine $2.5 \mathrm{mg}$ and prednisone $\mathrm{mg} / \mathrm{kg}$ were started, obtaining an increase in the granulocyte count 4 months later ${ }^{15}$. It suggests that plasmapheresis alone is not a good option for the treatment of PWCA and the use of concomitant inmunosupressor is needed.

Thymectomy is a major surgery with high complexity and infectious risks. We consider that the appropriate management would be the resolution of the PWCA prior to surgery. According to our review, treatments with immunosuppressive drugs are associated with better outcome. In our patient, we have obtained a good response with CyA, which supports the existing literature as the most successful therapeutic option. Furthermore, it is a drug with a known safety profile, extensive experience in its use and the possibility of measuring levels. Therefore, we suggest the use of CyA as a first-line drug with the concomitant use of G-CSF from granulocyte recovery onwards. Long-term follow-up of thymoma and immunological status is advisable because relapses have been observed in these patients.

Conflict of interest : Authors report no conflicts of interest associated with this publication. 
Author contributions : Roberto Céspedes López is the main author, was involved in patient care, provided necessary data for the article, and was involved in manuscript preparation. Elena Amutio Díez is the main reviewer, was involved in manuscript preparation, checked grammatical and data errors, and patient care. Xabier Martín Martitegui was involved in patient care and provided data for the article. Amaia Balerdi Malcorra was invoveld in patient care. Lucía Insunza Oleaga was involved in patient care. Maite Moreno Gámiz was involved in patient care. Javier Arzuaga Méndez was involved in patient care. Juan Carlos García-Ruíz checked the manuscript for grammatical and secientific errors.

Ifrah Malik checked the manuscript for grammati-cal and scientific errors

Ethical approval: Appropriate informed consent was taken for publication of this report and the associated images. Authors have confirmed that patient consent has been signed and collected in accordance with the journal consent policy.

\section{References}

1. Curtis BR. Non-chemotherapy drug-induced neutropenia: key points to manage the challenges. Hematology Am Soc Hematol Educ Program 2017;8:187-193.

2. Verley JM, Hollmann KH. Thymoma. Comparative study of clinical stages, histologic features, and survival in 200 cases. Cancer 1985;55:1074-1086

3. Yip D, Rasko J.E.J, Lee C, et al. Thymoma and agranulocytosis: Two case reports and literatura review. Br J Haematol. 1996 Oct;95:52-56

4. Guevara-Hoyer K, Fuentes-Antrás J, Calatayud Gastardi J, et al. Immunodeficiency and thymoma in Good síndrome: Two sides of the same coin. Immunol Let 2021;231:11-17.

5. Levitt LJ, Ries CA, Greenberg PL. Pure white-cell aplasia. Anti-body-mediated autoinmune inhibition of granulopoiesis. N Engl \souta J Med 1983;308:1141-1146

6. Kobayashi Y, Ando K, Hata T, et al. Complete remission of pure white cell aplasia associated with thymoma after thymectomy and cyclosporine administration. Int J Hematol Int J Hematol 2018;109:346350.

7. Thapa P, Farber D.L. The role of the thymus in the immune response. Thorac Surg Clin. 2019;29: 123-131

8. Shelly S, Agmon-Levin N, Altman A, et al. Thymoma and autoimmunity. Cell Mol Immunol 2011;8: 199-202

9. Kobayashi M, Hasegawa T, Iwabuchi S, et al. The effect of thymectomy on myasthenia gravis, thrombocytopenia, and granulocytopenia associated with thymoma: report of a case. Surg Today 1995;25:1061-1065

10. Uy K, Levin E, Mroz P, et al. A rare complication of thymoma: pure white cell aplasia in Good's Syndrome. Case Rep Hematol 2019;13:102467

11. Degos L, Faille A, Housset M, et al. Syndrome of neutrophil agranulocytosis, hypogammaglobulinemia and thymoma. Blood 1982;60:968-72.

12. Fumeaux Z, Beris P, Borisch B, et al. Complete remission of pure white cell aplasia associated with thymoma, autoinmune thyroiditis and type 1 diabetes. Eur J Haematol 2003;70:186-189

13. Risitano AM, Selleri C, Torelli GF, et al. Alemtuzumab is safe and effective as immunosuppressive treatment for aplastic anaemia and single-lineage marrow failure: a pilot study and a survey from the EBMT WPSAA. Br J Haematol2010;148:791-6

14. Alvares CL, Svasti-Salee D, Rowley M. Remission induced by Campath-1H for thymoma-associated agranulocytosis. Ann Hematol 2004;83:389-400 
15. Mathieson PW, O`Neill JH, Durrant STS, et al. Antibody-mediated pure neutrophil aplasia, recurrente myasthenia gravis and previous thymoma: case report and literature review. Q J Med 1990;74:57-61.

\section{Hosted file}

Figura 1.docx available at https://authorea.com/users/437557/articles/539109-pure-whitecell-aplasia-an-exceptional-condition-in-the-inmunological-conundrum-of-thymomasresponses-to-inmunosupresion-and-literature-review

\section{Hosted file}

Figura 2.docx available at https://authorea.com/users/437557/articles/539109-pure-whitecell-aplasia-an-exceptional-condition-in-the-inmunological-conundrum-of-thymomasresponses-to-inmunosupresion-and-literature-review

\section{Hosted file}

Tabla_01.docx available at https://authorea.com/users/437557/articles/539109-pure-whitecell-aplasia-an-exceptional-condition-in-the-inmunological-conundrum-of-thymomasresponses-to-inmunosupresion-and-literature-review 